\title{
Interpelações do pensamento decolonial à missão cristã
}

\section{Interpellation of decolonial thought to the Christian mission}

Stefano Raschietti

\section{Resumo}

Nesse ensaio apresentaremos as linhas constitutivas do pensamento decolonial, que apresenta a colonialidade como o "lado escuro" da modernidade, intrinsecamente associada aos propósitos emancipadores do Ocidente cristão. Esse pensamento se configura como uma obra coletiva em construção, que afunda suas raízes na tradição crítica anticolonial latinoamericana, agrupando produções heterogêneas de diversos autores num âmbito interdisciplinar. Elemento de gravitação e de agregação de todo o programa é o conceito de "colonialidade do poder" que se desdobra em "colonialidade do saber" e "colonialidade do ser", formando assim uma "estrutura triangular", a expressar principalmente a dimensão política, epistemológica e ontológica do objeto em questão. Os aportes desse projeto oferecem para uma teologia da missão intuições e elementos analíticos críticos que delineiam quatro âmbitos de indagação: a irrupção do "outro" como sujeito interlocutor; a necessidade de um processo epistêmico de desprendimento e abertura; a exigência primeira da missão habitar a fronteira; o compromisso junto aos projetos decoloniais globais. Enveredar pelo caminho decolonial implica para a prática e a teologia da missão uma radical mudança de orientação e motivação.

Palavras-chave: Missão. Missiologia. Decolonialidade. América Latina. Interculturalidade.

\section{Abstract}

This essay will present the constitutive lines of Latin American decolonial thought, which presents coloniality as the "dark side" of modernity, intrinsically associated with the emancipatory purposes of the Christian West. 
This thought is configured as a collective work under construction, which has its roots in the Latin American anti-colonial critical tradition, grouping heterogeneous productions by different authors in an interdisciplinary scope. An element of gravitation and aggregation of the entire program is the concept of "coloniality of power" that unfolds into "coloniality of knowledge" and "coloniality of being", thus forming a "triangular structure", expressing mainly the political, epistemological and ontological dimension of the object in question. The contributions of this project offer intuitive insights and critical analytical elements for a theology of mission that outline four areas of inquiry: the irruption of the "other" as an interlocutor; the need for an epistemic process of detachment and openness; the primary requirement of the mission to inhabit the border; commitment to global decolonial projects. Going down the decolonial path implies a radical change in orientation and motivation for mission practice and theology.

Keywords: Mission. Missiology. Decoloniality. Latin America. Interculturality.

\section{Introdução}

Um dos mitos do século XX foi a noção de que a eliminação das colônias do Terceiro Mundo representava um processo de descolonização e o começo de uma época "pós-colonial". Todavia, as estruturas globais múltiplas e heterogêneas estabelecidas ao longo de um período de 450 anos, não se evaporaram com a descolonização política da periferia nos últimos 50 anos: "continuamos a viver sob as sombras do mesmo 'padrão colonial de poder'; com a descolonização política, passamos de um período de 'colonialismo global' para o período atual de 'colonialidade global"."

Isso quer dizer que o mesmo sistema se propõe agora não mais sobre as feições de um colonialismo histórico, brutal e genocida, nem sob a forma de um imperialismo formal igualmente violento e opressor, mas sob a condição de uma colonialidade mais sutil e sedutora que mantem e consolida uma estrutura hierárquica de classificação, submissão e exploração da população mundial. Não há mais uma dominação explícita por parte de um reino ou de um estadonação, agora evanescentes, e sim a hegemonia de um capitalismo financeiro estruturalmente e progressivamente desregulamentado, liderado pelos Estados

${ }^{1}$ GROSFOGUEL, R., La descolonización de la economía política y los estudios postcoloniales, p. 28. 
Unidos, que se expressa na maioria das vezes de maneira informal, imperceptível e nebulosa. ${ }^{2}$

A missão cristã tradicionalmente foi aliada do projeto colonial do ocidente. $^{3}$ Esse dado histórico inequívoco é motivo para um permanente discernimento estrutural e penitencial: nos últimos quinhentos anos, não há missão cristã sem colonização ocidental e vice-versa: como se repropõe hoje essa relação? Sob quais vestes, fantasias ou máscaras?

Nesse ensaio apresentaremos as linhas constitutivas do pensamento decolonial latino-americano, que apresenta a colonialidade como o "lado escuro" da modernidade, ${ }^{4}$ intrinsecamente associada aos propósitos mais emancipadores do Ocidente cristão, e seu desdobramento na colonialidade do poder, do saber e do ser. Em seguida, abordamos algumas pistas de reflexão para um discurso crítico sobre a missão cristã: o significado da irrupção "do outro" como sujeito; o necessário processo de desprendimento e abertura; a relevância do contexto geo-político da fronteira; os projetos decoloniais que se conectam com o projeto de Jesus é instaurar o Reino de seu Pai. ${ }^{5}$

\section{Os eixos constitutivos do pensamento decolonial}

No final dos anos 90, alguns intelectuais latino-americanos de diversas universidades do Continente e dos Estados Unidos, formaram um grupo de pesquisa interdisciplinar que se autodenominou "Grupo Modernidade/Colonialidade" (M/C). ${ }^{6}$

\footnotetext{
${ }^{2}$ BALlESTRIN, L. M. A., A Modernidade/Colonialidade sem “Imperialidade"?, p. 516.

${ }^{3}$ Com o Vaticano II e a tradição eclesial latino-americana desde Medellín há um certo esforço de descolonização da atuação missionária, mas há sempre o risco incumbente de que novas formas de colonialidade militante reaparecerem, "com a roupagem de um novo linguajar, os velhos vícios" (SUESS, P., Companheiro-peregrino na Terra dos Pobres, p. 649).

${ }^{4}$ MIGNOLO, W., Desobediencia epistémica, p. 9.

${ }^{5}$ DAp 361.

${ }^{6}$ Entre eles: Aníbal Quijano, sociólogo da Universidad Nacional de São Marcos, Peru; Arthuro Escobar, antropólogo colombiano da University of North Carolina, EUA; Boaventura de Sousa Santos, sociólogo da Universidade de Coimbra, Portugal; Catherine Walsh, linguista americana da Universidad Andina Simón Bolívar, Equador; Edgardo Lander, sociólogo da Universidad Central de Venezuela; Enrique Dussel, filosofo argentino da Universidad Nacional Autonoma de México; Fernando Coronil, antropólogo venezuelano da University of New York, EUA; Immanuel Wallerstein, sociólogo da Yale University, EUA; Nelson Maldonado-Torres, filosofo porto-riquenho da University of California, Berkeley, EUA; Ramón Grosfoguel, sociólogo portoriquenho da University of California, Berkeley, EUA; Santiago Castro-Gómez, filosofo da Pontificia Universidad Javeriana, Colômbia; Walter Mignolo, semiótico argentino da Duke University, EUA; Zulma Palermo, semiótica Universidad Nacional de Salta, Argentina.
} 
O programa de investigação deste coletivo gravitou em torno da categoria central da colonialidade como modelo hegemônico cognitivo que sobrevive ao colonialismo e ao imperialismo.

Por sua vez, a decolonialidade configura um processo que busca transcender historicamente a colonialidade, com o intento de subverter o poder colonial atual que domina no mundo, mesmo o colonialismo ter sido extinto como evento histórico.

O programa de investigação $\mathrm{M} / \mathrm{C}$ foi se estruturando ao longo de vários seminários, eventos, diálogos paralelos e publicações, partilhando noções, raciocínios, vocábulos, conceitos complexos que lhe conferiram uma identidade e uma terminologia própria, definindo uma série de problemáticas e de pautas de trabalho que adquiriram certa visibilidade em diversos cenários, configurando um projeto intelectual, como também político, que foi chamado de "projeto decolonial".

Os eixos cardeais que nos permitam adentrar o mare magnum das produções desse projeto, podem ser assim delineados.

\subsection{A colonialidade distinta do colonialismo e intrínseca à modernidade}

A noção de colonialidade foi introduzida por Aníbal Quijano (19302018) num artigo enxuto e denso de 1992, com o título Colonialidad y Modernidad-Racionalidad. Nesse ensaio, o sociólogo peruano afirma que "apesar do fato de o colonialismo político ter sido eliminado, a relação entre a cultura europeia, também chamada de 'ocidental' e as demais, continua sendo uma relação de dominação colonial”. Não se trataria, portanto, de uma simples subordinação das outras culturas à cultura europeia, mas de uma autêntica colonização do imaginário dos dominados: "Ou seja, atua dentro desse imaginário. Em uma medida, faz parte disso". 7

A colonialidade consiste em uma estrutura complexa de relações de poder centro-periferia em escala mundial, que tocam não apenas a ordem econômica, mas também a política, a natureza, o gênero, a sexualidade, a subjetividade e o conhecimento. ${ }^{8}$ Para os teóricos decoloniais, principalmente a categoria raça se torna o princípio organizador da colonialidade em função da lógica de acumulação de capital, da economia política e da divisão internacional do trabalho do sistema capitalista mundial. ${ }^{9}$

\footnotetext{
${ }^{7}$ QUIJANO, A., Colonialidad y modernidad-racionalidad, p. 12.

${ }^{8}$ MIGNOLO, W., Desobediencia epistémica, p. 12.

${ }^{9}$ GROSFOGUEL, R., Hay que tomarse en serio el pensamiento crítico de los colonizados en toda su complejidad, p. 43.
} 
Desta maneira, entre colonialismo e colonialidade há também uma continuidade, no sentido que essas estruturas, geradas a partir do século XVI, continuam exercendo um papel fundamental no presente do capitalismo global. A colonialidade figura como inerente e imanente à modernidade, não como simples contingência histórica e menos ainda como "desvio" do projeto emancipador moderno. Pelo contrário, a colonialidade é a exterioridade constitutiva e não derivada da modernidade.

Não há modernidade (colonização do tempo) sem colonialidade (colonização do espaço). Não há o moderno sem o colonial: não pode existir uma dimensão sem a outra. Estamos diante de uma totalidade espaço-temporal segundo a qual todas as civilizações não-europeias são geograficamente "periferias-atrasadas" em relação a um "centro-avançado" da história mundial. Ao definir um tempo (moderno vs. atrasado) e um espaço (centro vs. periferia), ao traçar umas metas na história e uns contornos nos mapas, se define quem está dentro e quem está fora, quem é civilizado e quem é selvagem, quem somos nós e quem são os outros.

\subsection{Crítica aos discursos euro-centrados e intra-moderno sobre a modernidade}

Do vínculo entre modernidade e colonialidade, surge o questionamento sobre a real natureza da modernidade, bem como a perspectiva filosófica e sociológica a partir da qual se enxerga o mundo moderno ocidental e seu processo de globalização. As narrativas que circulam sobre a modernidade são resultado de enfoques auto-referenciais e euro-centrados que afirmam, substancialmente, que a modernidade pode ser explicada por referência a fatores históricos (Revolução Francesa e revolução industrial), sociológicos (surgimento dos Estados-nação), culturais (racionalização) e filosóficos (emancipação do indivíduo), intrínsecos à Europa.

Segundo essa visão, a modernidade se originaria substancialmente a partir do Velho Continente e dali se difundiria para o mundo inteiro, sem contar que o próprio é resultante de um sistema geopolítico de relações de domínio que foram decisivas para o seu desenvolvimento. Sem as colônias a modernidade não teria existido, não apenas pelos aportes vitais das commodities, particularmente o açúcar, o chá, o cacau, o tabaco, etc., mas também porque com a introdução desses recursos, houve uma mudança de hábitos alimentares da população europeia que possibilitou e alavancou as diversas revoluções industriais, comerciais e socioculturais. Da mesma forma, a produção em larga escala de produtos agrícolas, constituiu uma forma 
precursora de organização capitalista em território colonial, quase como um laboratório, antes que esse processo começasse na própria Europa. ${ }^{10}$

Já Enrique Dussel critica o mito da modernidade do qual se origina um rito sacrifical. Com efeito, por um lado a modernidade se autodefine como emancipação pela razão, por outro, externa uma práxis irracional contra a outra cultura rotulada como não-moderna, inferior, rude, bárbara, sempre sujeita a uma "imaturidade" culpável. Ao atribuir uma culpa à pretensa bestialidade dos nativos das colônias, a modernidade justifica sua agressão, muitas vezes como um $a$ priori para criar as condições para um "diálogo": a guerra, então, seria justa e necessária para iniciar uma argumentação e um processo civilizatório com essas populações "atrasadas"."

\subsection{Pensar em termos de sistema-mundo}

A partir destas considerações, a perspectiva analítica e geopolítica adotada pelo programa de investigação $\mathrm{M} / \mathrm{C}$ não é a nação, o país ou o continente, e sim o conceito do sistema-mundo moderno, cunhado por Immanuel Wallerstein (1930-2019) para descrever a configuração da modernidade como uma "economia-mundo" capitalista, organizada em centro, semiperiferia, periferia. No primeiro e seminal volume de sua obra monumental, esse sociólogo norte-americano afirma que esse sistema-mundo nasceu no século XVI com a "descoberta" de um "Novo Mundo".

Para Wallerstein, o sistema-mundo moderno não é consequência de uma história linear que se desenvolveu de forma natural, mas do resultado de múltiplas e complexas interações de um conjunto de fenômenos relacionados entre si, particularmente: o surgimento do capitalismo como sistema econômico; a evolução da ciência e da tecnologia, fruto do intercâmbio com outras civilizações; a secularização da vida social, pela importância que a racionalização adquiriu nas diversas esferas da vida; a formação dos estadosnação, inclusive de estados dependentes das metrópoles (as colônias); o universalismo, como princípio de partilha de visões, conhecimentos e valores entre povos e pessoas, mas que historicamente tomou a forma de imposição por parte da modernidade e de sua retórica salvacionista. ${ }^{12}$

Desta maneira, a articulação desse sistema mundial não gerou apenas um processo de "acumulação original", mas também a formação de uma primeira cultura ou estrutura simbólica mundial que sancionava a classificação da

\footnotetext{
${ }^{10}$ MINTZ, S. W., Dulzura y poder.

${ }^{11}$ DUSSEL, E., 1492 O Encobrimento do outro.

${ }^{12}$ MIGNOLO, W., La colonialidad, p. 43.
} 
população com base em um critério étnico-racial e a hegemonia de uma racionalidade que afirmava a superioridade do homem-barão europeu. Influenciada pela teoria da dependência latino-americana, a obra de Wallerstein negava aos estados nacionais o estatuto de sociedades relativamente autônomas, "pois, eles foram e são, em primeiro lugar, estruturas criadas por processos de escalas mundiais e moldadas como uma reação a elas". ${ }^{13}$

\subsection{Consolidar um projeto decolonial}

A crítica epistémica do programa de investigação $\mathrm{M} / \mathrm{C}$ não somente busca problematizar a modernidade, suas narrativas e suas estruturas de poder, mas aponta também a um projeto ético e político decolonial, que tende a visibilizar a multiplicidade de conhecimentos, formas de ser e aspirações dos povos: uma pluriversalidade no lugar de uma universalidade.

Esse deslocamento na maneira de compreender a modernidade procura resgatar não apenas as diferenças culturais, mas também as diferenças coloniais negadas pela colonialidade do poder a partir do século XVI, de vozes silenciadas, de memórias fraturadas, de histórias contadas de um lado que suprimiam outras memórias e histórias.

Daí que não somente a colonialidade, mas também a decolonialidade é constitutiva da modernidade:

se a colonialidade é constitutiva da modernidade, uma vez que a retórica salvacionista da modernidade já pressupõe a lógica opressiva e condenatória da colonialidade (daí os damnés de Fanon), essa lógica opressiva produz uma energia de descontentamento, desconfiança e desapego entre aqueles que reagem à violência imperial. Essa energia se traduz em projetos descoloniais que, em última instância, também são constitutivos da modernidade. ${ }^{14}$

Assim sendo, o colonialismo deu origem a rupturas e descontinuidades que surgiram da tirania linear do progresso ocidental, e que configuraram uma nova prática epistêmica produzida pelos sujeitos à margem do regime estabelecido. Trata-se de um pensamento crítico plural assentado sobre as histórias marcadas pela violência colonial, que resgata o potencial da alteridade negada e que aponta para a diversidade como projeto universal. Essa abordagem não quer fazer da diferença colonial um "objeto de estudo", e sim

${ }^{13}$ WALLERSTEIN, I., Impensar las ciencias sociales, p. 85.
${ }^{14}$ MIGNOLO, W., El Pensamiento Decolonial, p. 26. 
um pensar a partir da dor da diferença colonial, revelando uma descontinuidade na história da modernidade e introduzindo uma perspectiva oposta, por parte de quem acredita que "a colonialidade originou olhares de raiva, necessidade de libertação, reação à arrogância e cegueira, tanto pela crueldade de alguns quanto pela bondade de outros". ${ }^{15}$

\section{O tratado sobre a colonialidade}

O pensamento decolonial se configura ainda como uma obra coletiva em construção, um canteiro aberto a novas e diversas contribuições, que afunda suas raízes na tradição crítica anticolonial latino-americana, agrupando produções heterogêneas de diversos autores num âmbito interdisciplinar.

Elemento de gravitação e de agregação de todo o programa é a categoria da colonialidade do poder que se desdobra em colonialidade do saber e colonialidade do ser, formando assim uma "estrutura triangular" ${ }^{16}$ a expressar principalmente a dimensão política, epistemológica e ontológica do objeto em questão. Desta análise se desprendem caminhos de decolonialidade como perspectivas e horizontes utópicos de superação e de libertação de todo poder estruturado em torno da desigualdade, da discriminação, da exploração e da dominação. ${ }^{17}$

\subsection{A colonialidade do poder}

É um dos temas fundamentais amplamente utilizado pelo Grupo $M / C$, quase como uma referência obrigatória, que associa a dominação colonial política e econômica com a colonização do conhecimento e do imaginário: o controle da economia e da autoridade está relacionado às bases nas quais se assenta não apenas o conhecimento, mas a própria maneira de produzir conhecimento.

Esse processo implica, em primeiro lugar, a repressão dos padrões de significação das culturas locais, para impor outros padrões de maneira mistificada, seletiva e sedutora, para que os dominados, por sua vez, possam ter acesso às respectivas esferas de poder. Desta maneira, a europeização cultural se converte numa aspiração política de participar do poder colonial, e mais do que isso, numa interioridade estruturante da própria subjetividade. ${ }^{18}$

\footnotetext{
${ }^{15}$ MIGNOLO, W., Historias locales/diseños globales, p. 32.

${ }^{16}$ CASTRO-GÓMEZ, S., Decolonizar la universidad, p. 79. Apesar de citada por esses autores, não há um desenvolvimento temático da colonialidade da natureza.

${ }^{17}$ QUIJANO, A., Colonialidad y modernidad-racionalidad.

${ }^{18}$ RESTREPO, E.; ROJAS, A., Inflexión decolonial, p. 95.
} 
Num segundo momento, Quijano avança outra argumentação sobre a colonialidade do poder, passando da dominação através da hierarquização natural das culturas, à dominação mediante a hierarquização natural das raças. O elemento "raça" torna-se o fundamento sobre o qual se estabelece o padrão de dominação entre colonizadores e colonizados. A colonialidade do poder se configura assim como uma ideologia racial apta a manter uma estabilidade entre as transições históricas de modelos e sistemas de dominação, produzindo uma racionalidade que se estabelece como única, válida, universal e superior a todas as outras.

Essa estrutura de poder se articula como uma rede de relações sociais de exploração/dominação/conflito articuladas em função da disputa pelo controle de cinco âmbitos da existência social: (1) a economia e o trabalho; (2) a natureza e seus recursos; (3) a sexualidade e a reprodução; (4) a subjetividade e o conhecimento; (5) a autoridade e a coerção.

Contudo, um padrão de poder não se configura como uma totalidade absoluta constituída por elementos homogéneos que mantêm relações contínuas, lineares e unidirecionais. Ao contrário, existe uma articulação heterogênea histórico-estrutural composta por elementos que têm descontinuidade, incoerência e conflitualidade entre si, possibilitando uma transformação social a partir do conflito que pode surgir de cada uma das partes em relação ao conjunto.

\subsection{A colonialidade do saber}

Apesar de não ter sido objeto de uma elaboração cuidadosa, esse conceito apresenta uma série de elementos que remetem à subalternização de uma multiplicidade de conhecimentos que não respondem às modalidades de produção do conhecimento ocidental, associadas a racionalidade moderna e à ciência convencional.

A objetividade e a neutralidade pressupõem um conhecimento sem sujeito, ou melhor, um conhecimento onde o sujeito toma distância de si para não contaminar o objeto com sua subjetividade. Esse distanciamento é necessário na racionalidade moderna para gerar um conhecimento válido e universal. Esse "não se situar" neutro apto a produzir um conhecimento universal, foi chamado por Santiago Castro-Gómez de hybris do ponto zero:

Como Deus, o observador observa o mundo a partir de uma plataforma de observação inobservada, a fim de gerar uma observação verdadeira e além da dúvida. Como o Deus da metáfora, a ciência ocidental moderna está situada fora do mundo (no ponto zero) para observar o mundo, mas, 
diferentemente de Deus, não consegue ter uma visão orgânica sobre o mundo, mas apenas uma observação analítica. ${ }^{19}$

Com essa noção se questiona a pretensão do conhecimento não-situado, de-historicizado, de-corporalizado do paradigma epistémico ocidental constitutivo da colonialidade.

Essa epistemologia com pretensões universalistas, anda também de mãos dadas com a questão linguística, na maneira de privilegiar determinados idiomas na comunicação e na produção do conhecimento teórico, subalternizando outros como apenas produtores de folclore, mas não de pensamento. A hierarquia linguística, ou "linguocentrismo", na qual o eurocentrismo foi fundamentado, controla o conhecimento não somente pelo domínio das próprias línguas, mas também pelas categorias nas quais é baseada a estrutura do pensamento. De modo que todas as cosmologias e conhecimentos do mundo, em suas diferentes linguagens e epistemologias, tiveram que se rearticular em relação aos modos ocidentais de conhecer, de ser e de se expressar.

Walter Mignolo afirma que a racionalidade moderna foi construída em torno de duas línguas e pensamentos clássicos, grego e latim, e de seis línguas e pensamentos europeus e imperiais: italiano, castelhano, português, francês, alemão e inglês. Dessas seis línguas modernas, as três primeiras correspondem à primeira modernidade (Renascimento) e as outras três correspondem à segunda modernidade (Ilustração). O poder hegemônico desses idiomas nunca se configurou pelo número de falantes - afinal, o mandarim é ainda a língua mais falada do mundo -, e sim pelo domínio do saber, pela produção intelectual e pelas culturas do conhecimento acadêmico, expressão de um saber universal e superior. Desta maneira, o potencial epistémico de outros saberes foi silenciado ou, no melhor dos casos, foi reputado como "conhecimento local", objeto somente de curiosidade.

\subsection{A colonialidade do ser}

Diz respeito à dimensão ontológica da colonialidade do poder, ou seja, às consequências sobre a experiência vivida pelos seres humanos na relação colonial, seu impacto na existência tanto do dominado como do dominador.

A subjetividade moderna fundamenta sua epistemologia no ceticismo metodológico cartesiano, que tem como pressuposto o dualismo da res cogitans (o pensante) e res extensa (o objeto), por sua vez derivado da autoconsciência

${ }^{19}$ CASTRO-GÓMEZ, S., Decolonizar la universidad, p. 83. 
do cogito ergo sum. Segundo Enrique Dussel, esse ego cogito do pensador do século XVII é antecipado pelo ego conquiro do conquistador do século XVI: o primeiro é a expressão ontológica do segundo. ${ }^{20}$ A certeza do sujeito prático em sua tarefa de apropriação de territórios, precedeu a certeza do sujeito pensante na apropriação do ser e do conhecimento, assim como a diferença colonial entre o ego conquistador e o ego conquistado não somente se antepôs, e sim inspirou o maniqueísmo da res cogitans (mente) e res extensa (corpo).

Sob esta ótica, ao perguntar se o outro "é realmente humano", se "é realmente racional", se "tem alma", se "tem direitos", o ceticismo metodológico cartesiano se torna fundamentalmente misantrópico e revela, inequivocavelmente, o fundamento da racionalidade instrumental moderna do ego conquiro:

Debajo del "yo pienso" podríamos leer "otros no piensan", y en el interior de "soy" podemos ubicar la justificación filosófica para la idea de que "otros no son" o están desprovistos de ser. De esta forma descubrimos una complejidad no reconocida de la formulación cartesiana: del "yo pienso, luego soy" somos llevados a la noción más compleja, pero a la vez más precisa, histórica y filosóficamente: "Yo pienso (otros no piensan o no piensan adecuadamente), luego soy (otros no son, están desprovistos de ser, no deben existir o son dispensables)". ${ }^{21}$

Desta maneira, se desdobra não somente uma diferença colonial, mas também uma diferença ontológica entre o ser e o que está abaixo do ser: a colonialidade do ser refere-se à violação do sentido de alteridade humana, ao ponto em que o alter-ego é transformado em um sub-alter, em um ser menor, em um ser que "não-está-ai", contrariando o conceito heideggeriano do Dasein, o "ser-ai". Essa diferença ontológica, na ordem do ser, é o resultado de uma naturalização que transforma o outro não somente num não-sujeito concreto, mas também numa essência transcendental.

A ideia da colonialidade do ser encontra um precioso aliado em Emmanuel Levinas, para o qual o problema da filosofia ocidental não está no discurso sobre o ser, mas no esquecimento do Outro: na ontologia não há espaço para se pensar o Outro enquanto Outro, não há espaço para pensar o diferente. A ontologia é uma filosofia do poder, cúmplice da violência, da desumanização e do sofrimento, que não questiona o Mesmo. Para o filósofo lituano, o ponto de partida da filosofia não deve ser a ontologia e sim a ética,

${ }^{20}$ DUSSEL, E., 1492 O Encobrimento do outro, p. 53.

${ }^{21}$ MALDONADO-TORRES, N., Sobre la colonialidad del ser, p. 144. 
que se assenta no reconhecimento da relação entre $e u$ e o Outro, preservando tanto a unicidade do eu como a alteridade de outrem.

\section{Sinopse para um discurso crítico sobre a missão cristã}

Dessa breve explanação sobre o tratado decolonial, podemos evidenciar alguns elementos-chave que podem se tornar ferramentas úteis para um discurso crítico sobre a missão cristã. A teologia não constrói um saber totalizante: ela é chamada a dialogar constantemente com outras disciplinas, respeitando a autonomia de cada uma, não apenas pelo esforço de elaborar um discurso significativo, mas para avaliar o sentido de seu próprio discurso. Particularmente, a mediação sócio-analitica foi um expediente bastante empregado na América Latina por uma teologia voltada à praxe eclesial, com o objetivo de entender em profundidade a conjuntura histórica e a condição humana junto à qual poder interagir. ${ }^{22}$

O pensamento decolonial nos oferece algumas coordenadas para tecer um discurso: (a) a irrupção "do outro" como sujeito; (b) o processo de desprendimento e abertura; (c) o contexto geo-político da fronteira; (d) os projetos decoloniais.

\subsection{A irrupção do "outro" como sujeito}

O "outro", como categoria, é uma invenção eurocêntrica, uma entidade criada pelo "mesmo" num processo de construção de si mesmo. ${ }^{23}$ Não existe ontologicamente o "outro": esse é simplesmente o resultado de um enunciado, o mesmo enunciado que apelidou de "índios" os nativos das terras recémconquistadas. O "outro", então, era tudo o que não era "eu": inventou-se um externo (exterioridade) no processo de criar um interno, com o objetivo de salvaguardar um espaço seguro onde pudesse viver o enunciante.

A diferença colonial é produto do estabelecimento desta exterioridade. Mignolo chama os polos desta criação de humanitas (o sujeito moderno) e de anthropos (a alteridade colonial). A irrupção dos "outros" acontece quando o

\footnotetext{
${ }^{22}$ Sem dúvida, a Teologia da Libertação pertence à genuína tradição decolonial latino-americana. Mas os pensadores decoloniais levantam uma série de suspeitas sobre a TdL: "mudam os conteúdos, mas não mudam os termos" (MIGNOLO, W., Desobediencia epistémica, p. 33). Ou seja: os termos do discurso são sempre "salvacionistas" de cima para baixo: se antes era do missionário para o pagão para salvá-lo, agora é da igreja libertadora para o pobre (que não é ainda o "outro") para libertá-lo. Pode ser - e muitas vezes é - mais ou menos a mesma coisa pretensiosa.

${ }^{23}$ MIGNOLO, W., Habitar la frontera, p. 30.
} 
anthropos desobedece aos padrões de poder construídos artificialmente para ele, denuncia a suposta ontologia de tais categorias, se recusa a reivindicar cidadania na humanitas, reconstroi a própria dignidade a partir do anthropos, ou seja, do "bárbaro", do "pobre", do "oprimido", afirmando a própria identidade fronteiriça e esvaziando a pretensão de totalidade da humanitas.

Essa "colonialidade" da irrupção dos "outros" parte de cotidianos de sofrimentos, de injustiças, de desumanização, de negação, de experiência encarnada, histórica, contextual, carregada de vozes vivas, de memórias vividas. Na classificação humanitas/anthropos, a modernidade aparece claramente como a negação da relacionalidade ao impor uma representação unívoca do real, circunscrita no tempo e no espaço. O pensamento decolonial, ao contrário, tende a promover uma ampla, profunda e plural relacionalidade temporal e espacial, ${ }^{24}$ escutando vozes, ouvindo histórias, resgatando dignidade e esperança, promovendo re-existências, desmascarando o mito sacrifical da modernidade, ressuscitando a diferença colonial como elemento essencial para um mundo onde possam caber muitos mundos.

\subsection{O processo de desprendimento e abertura}

Para que essa diferença possa emergir para o debate epistêmico, o desprendimento é o primeiro passo rumo a um pensamento decolonial. Consiste em "desaprender", abandonar as formas de conhecer que configuram subjetividades nos moldes da retórica da superioridade ocidental, desapegar das ficções de verdade e de estética naturalizadas pela matriz colonial do poder. O segundo passo é a abertura a um pensamento-outro, "sentar-se em círculo para aprender" (Upanishad) a partir de outras racionalidades, de outras cosmovisões e de outras maneiras de ser, de saber e de fazer. Portanto, a opção teórica decolonial propõe uma dupla operação: por um lado, despir-se das arrogâncias ocidentais que colonizaram o conhecimento; por outro, dispor-se a uma nova maneira de pensar a partir de uma pluralidade de pontos de enunciação geohistoricamente situados. Desta forma, teremos uma descolonização epistemológica como reação ao pensamento ocidental e sua reivindicação universal, através de uma valorização de conhecimentos rechaçados pela hegemonia eurocêntrica. Em suma, trata-se de aprender a desaprender (desprendimento) para reaprender de outra maneira (abertura).

O que exatamente se pretende com esta manifestação não é promover uma nova abstração ou uma nova formulação de um conhecimento teórico, um falar

${ }^{24}$ MELKEN, R. V., Colonialidad y relacionalidad. 
sobre o "outro", mas a um sentipensar, um corazonar, um tocar com as mãos "as pegadas da ferida colonial de onde se tece o pensamento descolonial", um experienciar vivencialmente caminhos passando por "portas que conduzem a outro tipo de verdades, cujo fundamento não é o ser, mas a colonialidad do ser". 25

Os teóricos decoloniais acusam o cristianismo de mudar o conteúdo, mas não os termos do discurso: assim a "cristianização" no século XVI se tornava "civilização" no século XIX, "desenvolvimento", "libertação", "evangelização" no século XX. Sempre despontava de alguma maneira uma direção hegemônica: dos missionários para os pagãos, bárbaros, atrasados, pobres, afastados. Desprendimento e abertura significaria aqui se despir de uma postura docente para enveredar decididamente pelo caminho da reciprocidade simétrica intercultural, inter-religiosa, inter-espiritual.

\subsection{O contexto geo-político da fronteira}

Pensar a partir da alteridade aponta para uma subversão epistêmica e política que só é possível se nos situarmos geograficamente e geopoliticamente na margem, ou na exterioridade da hegemonia de um pensamento eurocentrado. A fronteira, como anota Carlos Alberto Motta Cunha, ${ }^{26}$ é um campo semântico interessante e também, por sua natureza, ambivalente. É feita ao mesmo tempo para separar e juntar, confrontar e encontrar, dividir e unificar, marginalizar e resgatar, delimitar e transgredir, identificar e diferenciar: "é nas fronteiras que se mede toda a terrível inquietude que atravessa a história da humanidade". ${ }^{27}$

Habitar a fronteira é uma opção ética e uma práxis histórica concreta que permite transpor os limites da totalidade propondo uma superação e uma abertura para uma novidade subversiva. Fazer da fronteira um lugar onde morar, propicia uma desobediência epistêmica, política e mestiça dos sujeitos que ali se encontram marcados pela ferida colonial. Gloria Anzaldúa (19422004) define a fronteira como uma ferida aberta ${ }^{28}$ uma lesão que não tem cura, um corte que não dá para costurar, um tecido vivo dilacerado do qual jorra o sangue da vida: sabedorias, misturas religiosas e multiculturais, novas subjetividades, novas relações, novas cosmovisões. Deixar sangrar é perpetuar a multiplicidade do ser. A imagem da fronteira como ferida aberta diz sobre a impossibilidade de ocultá-la.

\footnotetext{
${ }^{25}$ MIGNOLO, W., El Pensamiento Decolonial, p. 29.

${ }^{26}$ CUNHA, C. A. M., Teologia decolonial e epistemologia do Sul.

${ }^{27}$ CASSANO, F., Il pensiero meridiano, p. 53.

${ }^{28}$ ANZALDÚA, G., Borderlands - La Frontera.
} 


\subsection{Os projetos decoloniais globais}

Os caminhos abertos pela irrupção do "outro", pelo desprendimento, pela desobediência política e epistémica, pelo habitar a fronteira, apontam para um "ter que viver em um mundo que é como é, trabalhar não para mudar o mundo, mas para construir um outro a partir das ruínas do mundo em que vivemos". ${ }^{29}$ O horizonte descrito pelos projetos decoloniais é sensivelmente diferente da otimística perspectiva do progresso e do desenvolvimento, como também dos bons propósitos voluntaristas eurocentrados de um mundo melhor.

O termo apocalíptico "ruinas" não quer indicar aqui o aniquilamento de uma civilização, ou o desejo de seu malogrado fim, mas a redução crítica da glória do Ocidente, o desmantelamento da soberba dos arcos do triunfo, a "provincialização" da Europa, ${ }^{30}$ mesmo que certas categorias, idiomas, ferramentas conceituais e semânticas possam servir ainda, de alguma forma, como mediação (eis as ruinas).

Os projetos decoloniais identificam-se com aquilo que Boaventura de Sousa Santos chama de sociologias das emergências, as lutas populares e subalternas que buscam potencialidades e possibilidades para uma transformação social anticapitalista, anticolonialista e antipatriarcal, entretanto que as sociologias das ausências têm a tarefa de tornar possível a passagem da vitimização à resistência como momento de denúncia da realidade de exclusão. ${ }^{31}$ A epistemologia zulu do ubuntu ("eu sou porque tu és"), os conceitos quéchua de kawsay ("bem viver") e de Pachamama ("Mãe Terra"), as noções hindu e gandhianas de swaraj ("auto-determinação") e de ahimsa ("não violência"), são exemplos que "devem ser vistos como um contributo para a renovação e para a diversificação das narrativas e dos repertórios das utopias concretas de um outro mundo possível": ${ }^{32}$ histórias locais com vocação necessariamente global (uma vez que a colonialidade do poder atinge dimensões planetárias), articuladas pela ecologia dos saberes e pela tradução intercultural num movimento cosmopolita, ${ }^{33}$ pluriverso e subversivo, decolonizado epistemologicamente e desmercantilizado politicamente.

\footnotetext{
${ }^{29}$ MIGNOLO, W., Habitar la frontera, p. 393.

${ }^{30}$ CHAKRABARTY, D., Provincializzare 1'Europa.

${ }^{31}$ SOUSA SANTOS, B., O fim do império cognitivo, p. 53.

${ }^{32}$ SOUSA SANTOS, B., O fim do império cognitivo, p. 33.

${ }^{33}$ SOUSA SANTOS, B., O fim do império cognitivo, p. 59
} 


\section{Conclusão}

Enveredar por este caminho decolonial implica para a prática e a teologia da missão uma radical mudança de orientação e motivação: de uma concepção de missão como "expansão", para uma compreensão de missão como um genuíno e profundo "encontro" com os outros. ${ }^{34}$ Ao contrário de visualizar as pessoas a serem catequizadas como "objetos" ou "alvos" de conversão, agora o desafio é de reconhecê-las simetricamente e dignamente como interlocutoras, portadoras também de uma mensagem de salvação.

Desta maneira, as tarefas primeiras talvez sejam: a) desmascarar a cumplicidade da missão com as relações coloniais na história e no presente; b) desenvolver ferramentas que ajudem a se defender contra a hegemonia epistemológica de uma teologia dominante; c) colocar sua produção a serviço dos subalternos e desenvolvê-la em diálogo com eles.

Os projetos decoloniais interessam enormemente à missão como iniciativas anti-sistêmicas que refletem a sabedoria e a vocação divina de cada povo, contra toda forma de violência e toda pretensão de domínio. Não se trata de querer negociar, ou confundir, verdades de fé com circunstâncias históricas, e sim se dispor a testemunhar o próprio âmago do Evangelho na proximidade a todas as realidades humanas, no diálogo político, intercultural e inter-religioso, na reciprocidade e na reconciliação, na promoção de sociedades mais justas e fraternas, na tensão esperançosa para uma comunhão pluriversal plena.

Envolver-se na perspectiva decolonial, intercultural e pluriversal significa assumir riscos e abrir-se para o inesperado. Isso não quer dizer optar pelo relativismo, mas pela profunda humildade e pela necessária aprendizagem: "com a modéstia do provisório e do inacabado, é urgente aprender, talvez por muito tempo, a arte da pluralidade dos discursos e de sua polifonia". ${ }^{35}$

\section{Referências bibliográficas}

ANZALDÚA, G. Borderlands - La Frontera. The new mestiza. San Francisco: Aunt Lute, 1987.

ARNOLD, S. P. Descolonización e Interculturalidad. El punto de vista teológico. Voices, v. 37, n. 1, p. 29-43, jan./abr. 2014. Disponível em: $<$ http://eatwot.net/VOICES/VOICES-2014-1.pdf>. Acesso em: 10 nov. 2017

${ }^{34}$ BEVANS, S. B.; SCHROEDER, R., Diálogo profético, p. 41.
${ }^{35}$ ARNOLD, S. P., Descolonización e Interculturalidad, p. 43.

PqTeo, Rio de Janeiro, v. 3, n. 5, p. 47-65, jan./jun. 2020 
BALLESTRIN, L. M. A. Modernidade/Colonialidade sem "Imperialidade"? O Elo Perdido do Giro Decolonial. DADOS - Revista de Ciências Sociais, v. 60, n. 2, p. 505-540, 2017. Disponível em: $<$ http://www.scielo.br/scielo.php?script=sci_abstract\&pid=S001152582017000200505\&lng=pt\&nr m=iso\&tlng=pt $>$. Acesso: 20 set. 2018. DOI: https://doi.org/10.1590/001152582017127

BEVANS, S. B.; SCHROEDER, R. Diálogo profético. Reflexões sobre a missão cristã hoje. São Paulo: Paulinas, 2016.

CASSANO, F. II pensiero meridiano. Bari: Laterza, 1996.

CASTRO-GÓMEZ, S. Decolonizar la universidad. La hybris del punto cero y el diálogo de saberes. In: CASTRO-GÓMEZ, S.; GROSFOGUEL, R. (Orgs.). El giro decolonial. Reflexiones para una diversidad epitémica más allá del capitalismo global. Bogotá: Siglo del Hombre / Universidad Central / IESCOUC / Pontifícia Universidad Javeriana / Instituto Pensar, 2007. p. 79-91.

CHAKRABARTY, D. Provincializzare l'Europa. Roma: Meltemi, 2004.

CUNHA, C. A. M. Teologia decolonial e epistemologia do Sul. Interações: Cultura e Comunidade, v. 13, n. 24, p. 306-333, ago./dez. 2018. Disponível em: $<$ file://C:/Users/User/Downloads/18518-Texto\%20do\%20artigo-69073-1-1020181231.pdf>. Acesso: 4 out. 2019. DOI: https://doi.org/10.5752/P.19832478.2018v13n24p306-333

DUSSEL, E. 1492 O Encobrimento do outro. A origem do "mito da modernidade". Petrópolis: Vozes, 1993.

GROSFOGUEL, R. Hay que tomarse en serio el pensamiento crítico de los colonizados en toda su complejidad. Entrevista a Luis Martínez Andrade. Metapolítica, v. 17, n. 83, p. 38-47, out./dez. 2013. Disponível em: $<$ http://www.boaventuradesousasantos.pt/media/Grosfoguel\%20METAPOLITICA _831.pdf>. Acesso: 31 out. 2018.

GROSFOGUEL, R. La descolonización de la economía política y los estudios postcoloniales. Transmodernidad, pensamiento fronterizo y colonialidad global. Tabula Rasa, n. 4, p. 17-46, jan./jun. 2006. Disponível em: $<$ http://www.scielo.org.co/pdf/tara/n4/n4a02.pdf>. Acesso: 19 out. 2018.

MALDONADO-TORRES, N. Sobre la colonialidad del ser: contribuiciones al desarrolho de un concepto. In: CASTRO-GÓMEZ, S.; GROSFOGUEL, R. (Orgs.). El giro decolonial. Reflexiones para una diversidad epitémica más allá 
del capitalismo global. Bogotá: Siglo del Hombre / Universidad Central / IESCOUC / Pontifícia Universidad Javeriana / Instituto Pensar, 2007. p. 127-167.

MELKEN, R. V. Colonialidad y relacionalidad. In: BORSANI, E.; QUINTERO, P. (Eds.). Los desafíos decoloniales de nuestros días: pensar en colectivo. Neuquén: Educo, 2014. p. 173-196.

MIGNOLO, W. Desobediencia epistémica. La retórica de la modernidad, lógica de la colonialidad y gramática de la descolonialidad. Buenos Aires: Ediciones del Signo, 2010.

MIGNOLO, W. El Pensamiento Decolonial: Desprendimiento y Apertura. Un manifesto. In: CASTRO-GÓMEZ, S.; GROSFOGUEL, R. (Orgs.). EI giro decolonial. Reflexiones para una diversidad epitémica más allá del capitalismo global. Bogotá: Siglo del Hombre / Universidad Central / IESCO-UC / Pontifícia Universidad Javeriana / Instituto Pensar, 2007. p. 25-46.

MIGNOLO, W. Habitar la frontera. Sentir y pensar la descolonialidad (Antología, 1999-2014). Barcelona: CIDOB, 2015.

MIGNOLO, W. Historias locales/diseños globales. Colonialidad, conocimientos subalternos y pensamiento fronterizo. Madrid: Akal, 2003.

MIGNOLO, W. La colonialidad: a cara oculta de la modernidad. In: BREITWIESER, S.; KLINGER, C.; MIGNOLO, W. Modernologías. Artistas contemporáneos instigam la modernidad y el modernismo. Barcelona: Museu d'Art Contemporani de Barcelona, 2009. p. 39-49.

MINTZ, S. W. Dulzura y poder [1985]. El lugar del azucar em la história moderna. Cidade do México: Siglo Veintiuno, 1996.

QUIJANO, A. Colonialidad y modernidad-racionalidad. Perú Indígena, v. 13, n. 29, p. 11-20, 1992. Disponível em: <https://www.lavaca.org/wpcontent/uploads/2016/04/quijano.pdf $>$. Acesso: 9 set. 2018.

RESTREPO, E.; ROJAS, A. Inflexión decolonial: fuentes concepto y cuestionamentos. Popayán: Universidad del Cauca, 2010.

SOUSA SANTOS, B. O fim do império cognitivo. A afirmação das epistemologias do Sul. Belo Horizonte: Autêntica, 2019.

SUESS, P. Companheiro-peregrino na Terra dos Pobres, Hóspede-Irmão na Casa dos Outros. Revista Eclesiástica Brasileira, v. 48, n. 191, p. 645-671, set. 1988. 
WALLERSTEIN, I. Impensar las ciencias sociales. Límites de los paradigmas decimonónicos. Coleção El mundo del siglo XXI. México: Siglo Veintiuno, 2003.

Stefano Raschietti ${ }^{36}$ Doutorando em Teologia na Pontifícia Universidade Católica do Paraná Curitiba / PR - Brasil E-mail: rasquio@yahoo.com.br

Recebido em: 03/04/20 Aprovado em: 19/06/20

${ }^{36} \mathrm{O}$ artigo é parte da pesquisa de doutorado em Teologia pelo Programa de Pós-Graduação em Teologia da Pontifícia Universidade Católica do Paraná, sob orientação do Prof. Dr. Pe. Agenor Brighenti. O presente trabalho foi realizado com apoio da Coordenação de Aperfeiçoamento de Pessoal de Nível Superior - Brasil (CAPES) - Código de Financiamento 001. 